\title{
Relationships between mean and standard deviation of air temperature: implications for global warming
}

\author{
Scott M. Robeson* \\ Department of Geography, Indiana University, Bloomington, Indiana 47405, USA
}

\begin{abstract}
Using data from the contiguous USA, the relationship between mean and standard deviation of daily air temperature was estimated on a monthly timescale from 1948 to 1997. In general, there is either an inverse relationship or a weak relationship between mean and standard deviation. For both daily maximum and daily minimum air temperature, the inverse relationship is spatially coherent for one-third to two-thirds of the contiguous USA for most months. The inverse relationship also is fairly strong, with typical reductions in standard deviation ranging from 0.2 to $0.5^{\circ} \mathrm{C}$ for every $1^{\circ} \mathrm{C}$ increase in mean temperature. A weaker, direct relationship between mean and standard deviation occurs in some northern states, primarily during spring and fall months. Using the predominant inverse and weak relationships as historical analogs for future climatic change suggests that interdiurnal variability of air temperature should either decrease or remain unchanged under warming conditions. Although the variability of air temperature may decrease or remain unchanged at most locations in the contiguous USA, the probability of extremely high air temperatures should still increase, depending on the magnitude of changes in mean air temperature and the nature of the variance response.
\end{abstract}

KEY WORDS: Climatic variability · Air temperature - Global warming $\cdot$ Probability distributions Resale or republication not permitted without written consent of the publisher

\section{INTRODUCTION}

Trends in observations of near-surface air temperature are among the most fundamental information used to detect recent climatic change. On a global scale, annual means of air temperature rose by nearly $0.6^{\circ} \mathrm{C}$ during the 20th century (IPCC 2001). Extremes of air temperature, as measured by the exceedance of thresholds such as values below $0^{\circ} \mathrm{C}$ or above $35^{\circ} \mathrm{C}$ for instance, also are of wide interest and importance (Cooter \& LeDuc 1995, Gaffen \& Ross 1999, Jones et al. 1999, Karl \& Easterling 1999, Easterling et al. 2000, Horton et al. 2001, Robeson 2002). It is impossible to determine the impacts of changes in mean air temperature on extremes, however, without simultaneously

*E-mail: srobeson@indiana.edu analyzing changes in the variance of air-temperature probability distributions (Mearns et al. 1984, Katz \& Brown 1992, Barrow \& Hulme 1996). In particular, evidence for changing numbers of days exceeding various air-temperature thresholds, such as the number of days below $0^{\circ} \mathrm{C}$ or above $35^{\circ} \mathrm{C}$, is particularly difficult to interpret if only mean air temperature is used as an explanatory variable.

In addition to its importance for extreme events, the detection of changes in air-temperature variance plays a fundamental role in helping us to understand how the climate system may be changing. The assumption that no change in the variability of air temperature will occur while mean air temperature changes can act as a 'null hypothesis' for recent and future climatic change (e.g. a translation rather than a change in shape of the normal distribution, as depicted in Karl et al. 1997). 


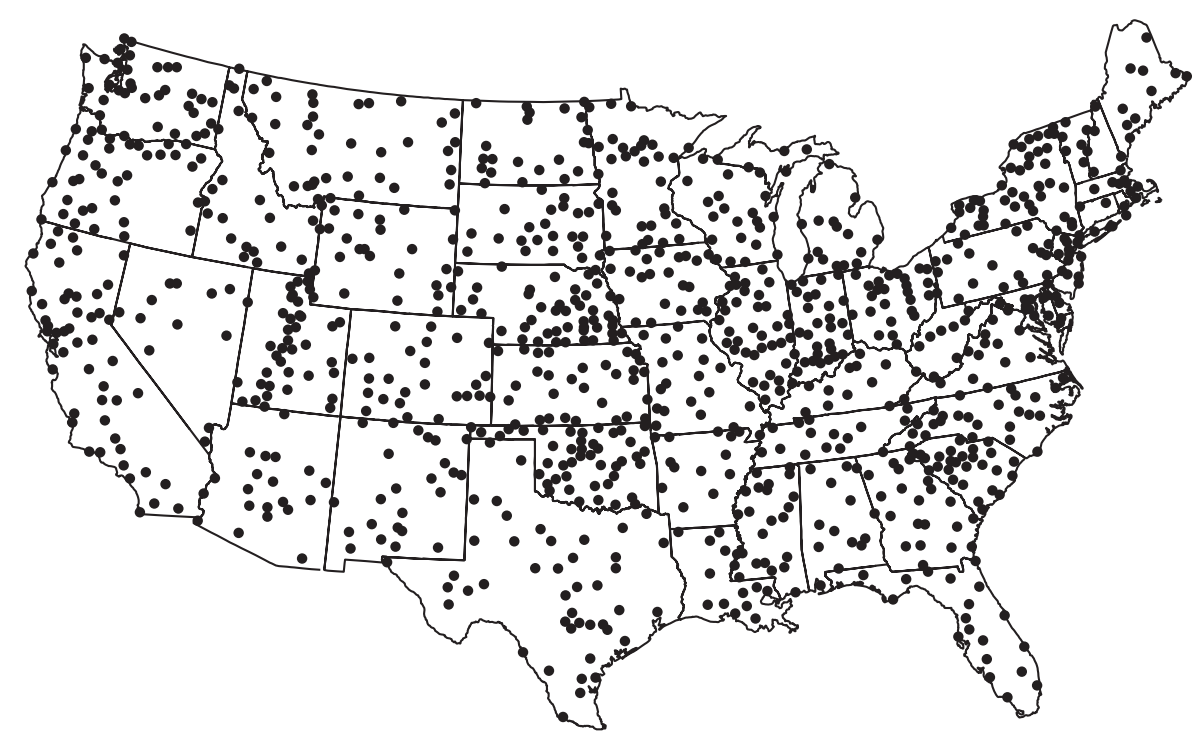

Fig. 1. Locations of stations in the daily US Historical Climate Network (HCND) that have records covering the period 1948-1997

Therefore, to evaluate how the standard deviation of air temperature has responded to changes in mean air temperature during the recent past, I estimated the slope of the relationship between mean and standard deviation of daily air temperature using data from over 1000 locations within the contiguous USA. This regression slope is termed the 'variance response'. Examination of the variance responses during the recent past establishes a foundation for better understanding recent climatic change, but also provides a historical analog (Glantz 1988, Henderson-Sellers 1986, 1992) that can be used to estimate the range of possible responses of the climatic system to global warming.

\section{DATA}

To address many important probabilistic questions regarding the nature and impacts of recent climatic change, daily air-temperature data are needed. Historical daily maximum and minimum air temperature $\left(T_{\max }\right.$ and $\left.T_{\min }\right)$ are available at 1062 cooperative climate stations in the contiguous USA (Fig. 1): the daily version of the US Historical Climate Network (HCND; Easterling et al. 1999). The HCND stations were selected for their long periods of record, relative high quality, and lack of urban bias (Karl et al. 1990). Nearly half of the stations in the HCND have daily digital records that start in 1948; therefore, 1948-1997 is the period of record for this analysis. Although the HCND data are considered to be of high quality, their climatic records may still contain a number of potential errors and biases (which are difficult or impossible to remove) that can influence estimates of air-temperature means and variability. These include station moves and changes in observing time, instrumentation, and site characteristics (Peterson et al. 1998). Since this study does not analyze temporal trends directly, any timedependent biases in the HCND have less impact than they would in change-detection research.

\section{ESTIMATING THE VARIANCE RESPONSE}

For every climate station in the HCND, the monthly mean and standard deviation of $T_{\max }$ and $T_{\min }$ were calculated from daily values for every month during the period 1948-1997. The linear response of the standard deviation to variations in mean air temperature then was estimated for each month using the principalaxis regression solution. (Mark \& Church [1977] and Davis [1986] note that the principal-axis solution also is known as the major-axis solution and is equivalent to finding the first eigenvector of the variance-covariance matrix between the 2 variables.) In this case, both mean air temperature (independent variable) and the standard deviation of air temperature (dependent variable) are subject to error; therefore, the principal-axis approach, whereby equal error is attributed to both variables, is more appropriate than ordinary leastsquares regression. In addition, because it is invertible, the principal-axis solution allows us to think alternately of both of these variables as the dependent variable: (1) change in variability may be caused by changes in mean air temperature or (2) changes in mean air temperature may be caused by changes in the variability of air temperature (in one of the tails). The slope of the ordinary least-squares solution is not 

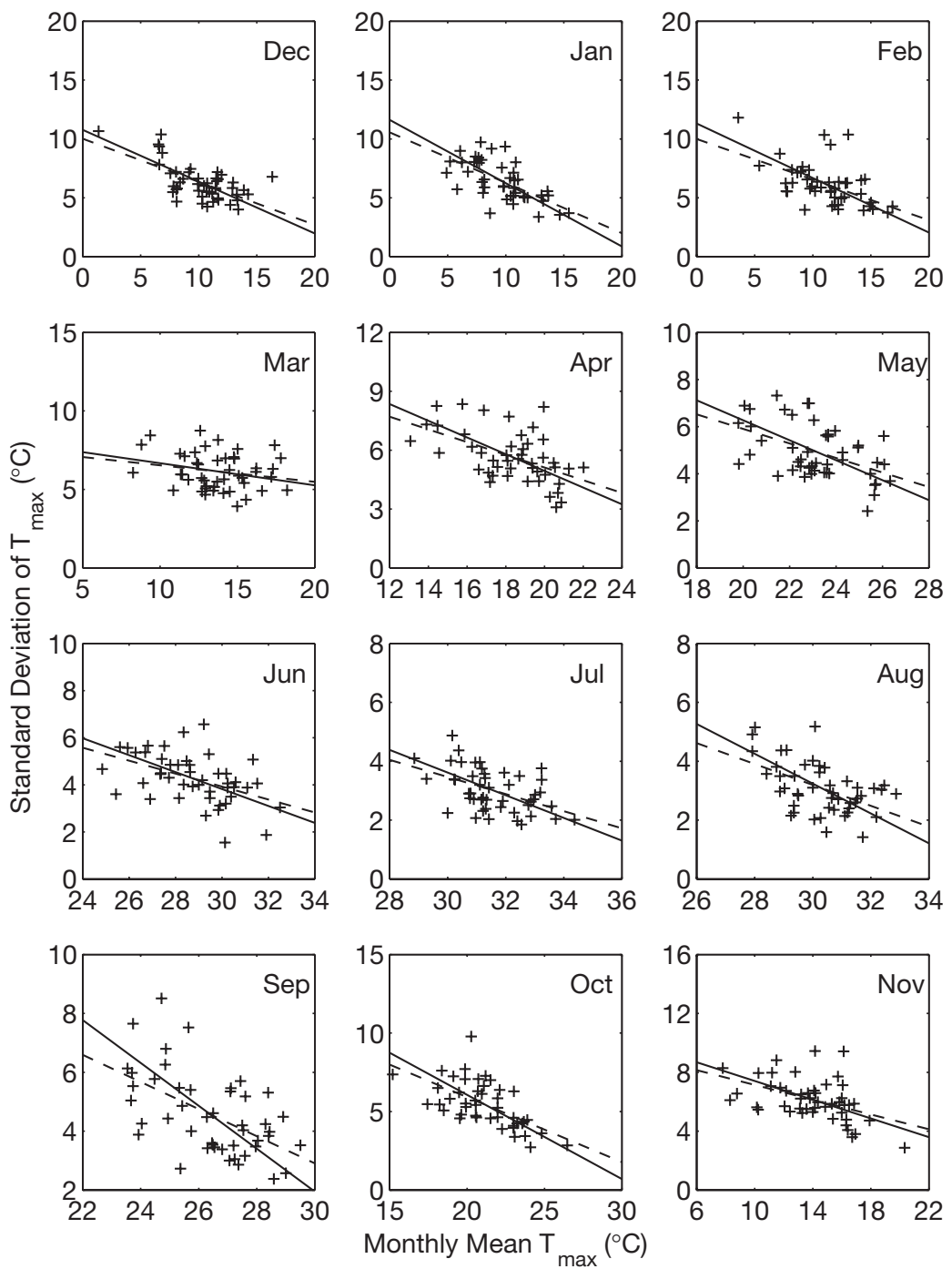

Fig. 2. Scatter plots of monthly mean maximum air temperature $\left(T_{\max }\right)$ versus monthly standard deviation of $T_{\max }$ for Canon City, Colorado, over the period 1948-1997. Solutions for both the principal-axis (solid line) and least-squares (dashed line) regressions are shown. The slope of the regression lines gives the variance response for each month. To allow comparison of regression slopes, the aspect ratio is 1:1 for all plots

invertible when interchanging independent and dependent variables. In either case, by estimating the variance response for every month and location separately, the slope of the relationship between the 2 variables is a direct result of historical climatic variability-rather than variability caused by latitudinal position or seasonality - and therefore serves as a useful analog for future conditions at that location.

As an example of a particularly strong varianceresponse relationship, $T_{\max }$ at Canon City, Colorado, shows a negative variance response for all months (Fig. 2). September has the largest variance response, with a value of -0.7 . The interpretation of this variance response is that each $1^{\circ} \mathrm{C}$ increase (decrease) in mean air temperature during September is associated with a decrease (increase) in the standard deviation of $0.7^{\circ} \mathrm{C}$ (as the slope estimate from regressing the standard deviation on mean air temperature, variance response is dimensionless). A climatic shift from a typical September at Canon City $\left(T_{\max }\right.$ of $26^{\circ} \mathrm{C}$ ) to a much warmer scenario $\left(30^{\circ} \mathrm{C}\right)$, therefore, could change the September standard deviation from $5^{\circ} \mathrm{C}$ to around $2^{\circ} \mathrm{C}$ (a standard deviation that is more typical of summer months at Canon City). As discussed above, the principal-axis regression solution allows the inversion of the slope estimate when the independent and dependent variables are virtually interchangeable. Therefore, one could also say that a $1^{\circ} \mathrm{C}$ decrease (increase) in standard deviation during September is associated with an increase (decrease) in mean air temperature of $1.4^{\circ} \mathrm{C}$. Because symmetric changes in variability do not cause a change in mean air temperature, the change in variability would have to occur preferentially on one side of the distribution.

The sign and strength of the variance response varies substantially by location and time of year; however, most stations have a negative variance response for most months. The frequency distribution of variance response shows that, for all months, the large majority of HCND stations have a negative response (Fig. 3). Winter and summer months produce the most consistent negative variance response, with more than $80 \%$ of stations having a negative response. Spring and fall months have the highest proportion of stations with a positive variance response, approaching $40 \%$ in some cases. $T_{\max }$ and $T_{\min }$ have similar frequency distributions, although $T_{\min }$ has a stronger negative response than $T_{\max }$ during January through March. $T_{\max }$ has a stronger negative response than $T_{\min }$ during May and October (Fig. 3).

\section{SPATIAL PATTERNS OF VARIANCE RESPONSE}

Initially, maps of the variance response at each station (by month) were viewed to evaluate the spatial homogeneity of the signals. Variance response is 

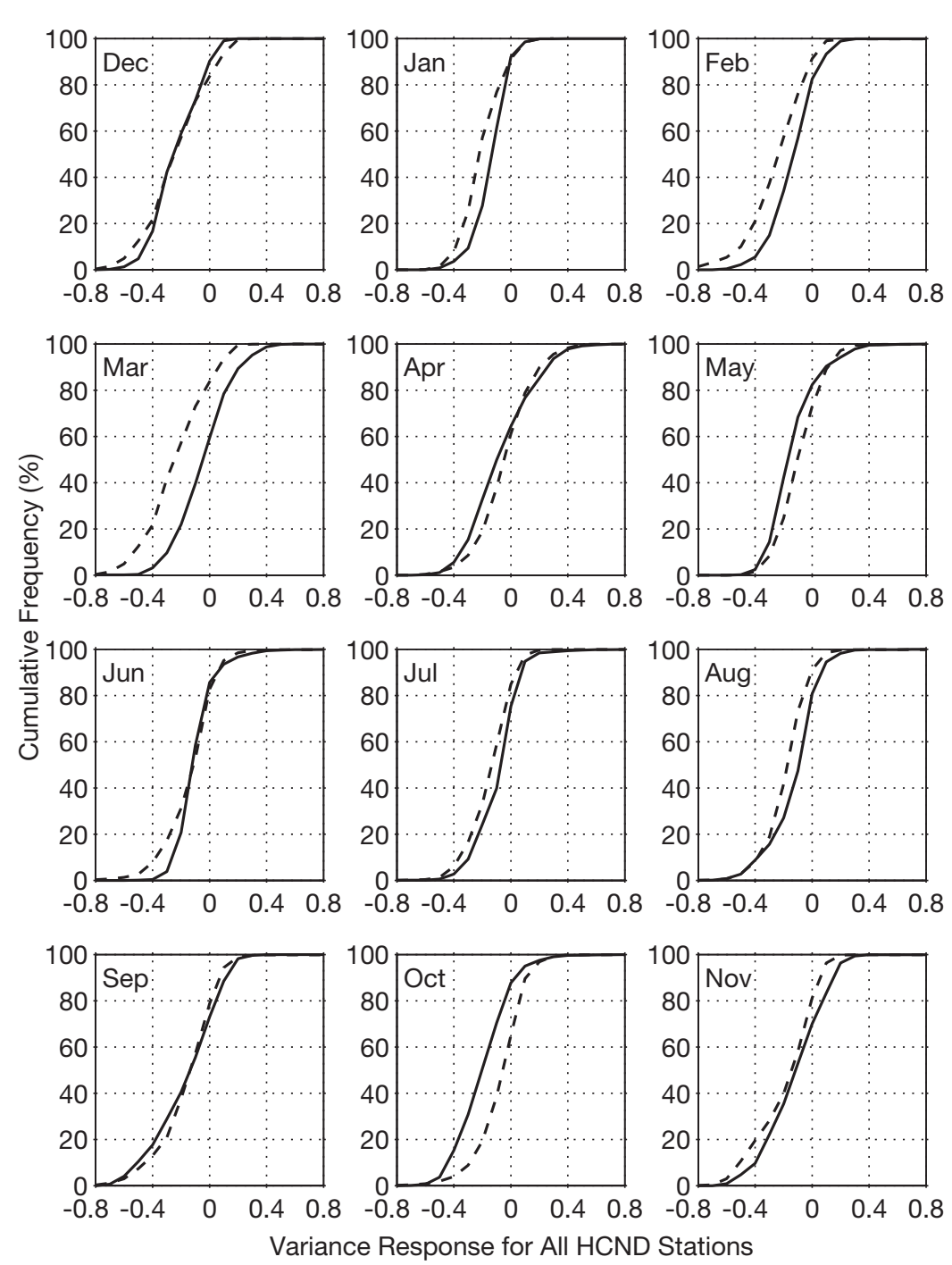

Fig. 3. Cumulative frequency distribution of the estimated variance response for all 1062 stations in the daily US Historical Climate Network (HCND) by month. In general, the cumulative distributions for both $T_{\max }$ (solid line) and $T_{\min }$ (dashed line) show that approximately $80 \%$ (or more) of the stations in any given month have a negative variance response. March (for $T_{\max }$ only), April, and October (for $T_{\min }$ only) have a higher frequency of positive variance response (approximately $40 \%$ ) than other months

remarkably consistent-regional patterns are evident and nearby stations typically have the same sign. To improve the visualization of spatial patterns, station values of variance response were averaged within $2^{\circ} \times$ $3^{\circ}$ latitude-longitude boxes (this box size was chosen as it was approximately the highest resolution grid that had at least 1 station within each box). Maps of the gridded variance response show that most of the contiguous USA has either no relationship or an inverse relationship between mean and standard deviation of air temperature for both $T_{\max }$ and $T_{\min }$ (Figs. $4 \& 5$ ). Regions that show a weak variance response (those with a ' + ' in Figs. 4 \& 5) would be expected to have approximately no change in air-temperature variability under a warming climate (or, alternatively, they do not have a consistent variance response during this $50 \mathrm{yr}$ period). For most months, however, approximately half of the contiguous USA has a negative variance response (Fig. 6), with magnitudes typically ranging between -0.2 and -0.5 . As a result, at these locations, an increase in mean air temperature of $1^{\circ} \mathrm{C}$ would typically be associated with a decrease in standard deviation of 0.2 to $0.5^{\circ} \mathrm{C}$. The negative variance response is slightly stronger in magnitude for $T_{\min }$ than for $T_{\max }$ however, its spatial coverage is similar for both variables. The location of the strongest response in $T_{\min }$ varies from the Northern Plains in winter and early spring to the Southeast in summer and early fall. The location of the strongest negative variance response in $T_{\max }$ also varies substantially by month, but is most prominent in the Plains, Mountain, and Southeastern states.

During some spring and fall months, portions of the northern tier of states have a spatially coherent positive variance response. The positive variance response is stronger and larger in spatial extent for $T_{\max }$ than it is for $T_{\min }$. The positive variance response in $T_{\max }$ predominantly occurs in the Pacific Northwest and Northeast during spring months. For $T_{\min }$, the positive variance response occurs primarily in the Great Lakes states during April, May, and October. A secondary positive variance response for $T_{\min }$ occurs in the Southeast during December. Coupled with a growing season that begins earlier, any increase in $T_{\min }$ variability in the Great Lakes during April and May could increase the probability of damaging late-spring freezes in that region, depending on how mean $T_{\min }$ changes (Robeson 2002). The positive variance response for $T_{\min }$ in the Southeast during December could have similar impacts. Overall, however, the positive variance response is smaller in spatial extent and magnitude than the negative response that occurs widely elsewhere. When spatially averaged, the positive variance response occurs over 10 to $20 \%$ of the contiguous USA for only a few months, 

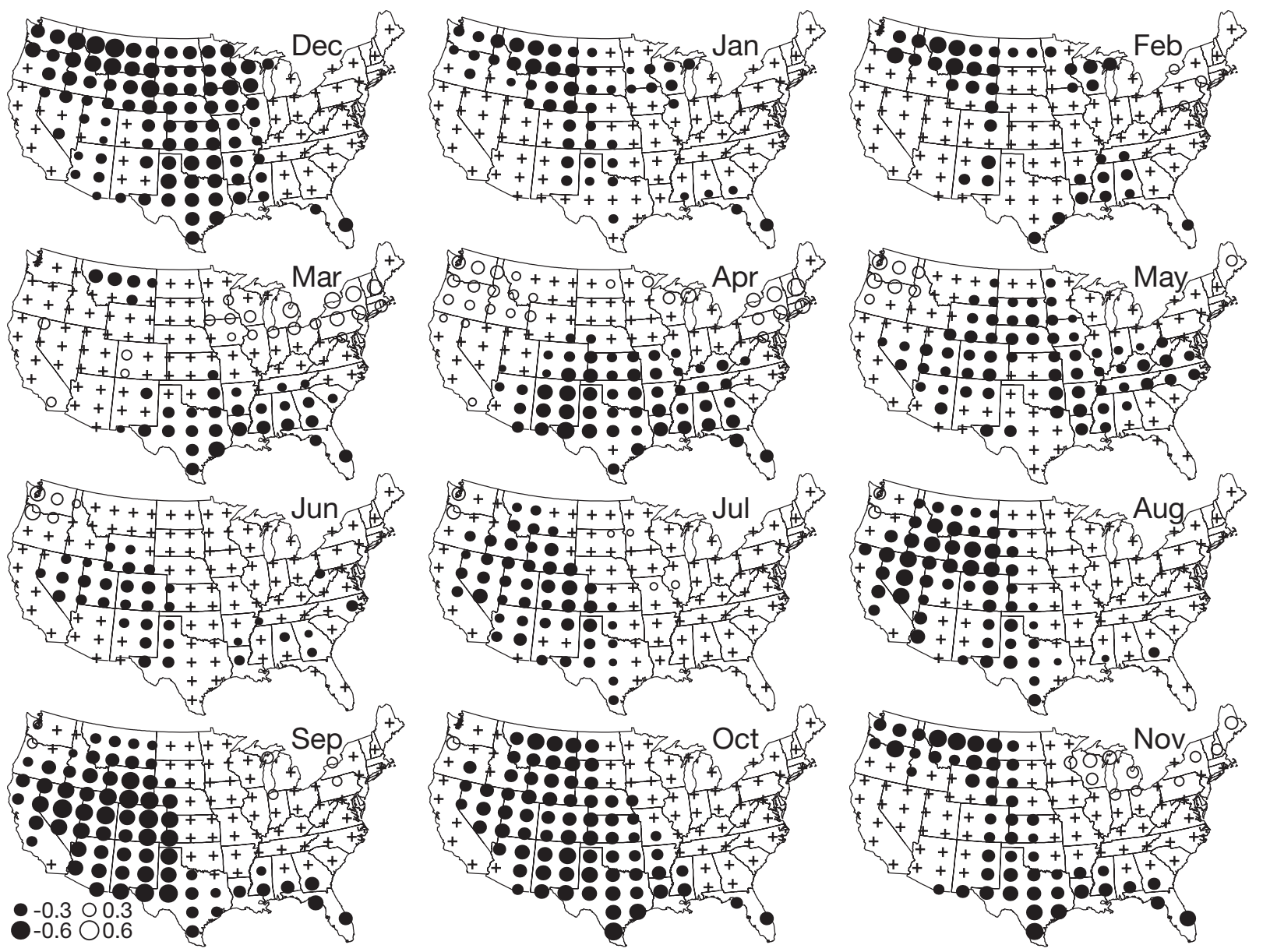

Fig. 4. Slope (dimensionless) of the response of monthly standard deviation to changes in monthly mean daily $T_{\max }$ on a $2^{\circ} \times 3^{\circ}$ latitude-longitude grid for the USA. A slope of -0.4 , for instance, indicates that an increase in monthly mean air temperature of $1^{\circ} \mathrm{C}$ is associated with a reduction in standard deviation of $0.4^{\circ} \mathrm{C}$. Gridded slopes that are not statistically significant (at the 0.10 level for a 2 -tailed $t$-test) are shown by a ' + '

while the negative variance response covers nearly 30 to $70 \%$ of the same area during most months (Fig. 6).

It should be noted that a precise level of statistical significance of the gridded variance response is difficult to establish. Regression slopes from multiple climate stations whose period of record is about $50 \mathrm{yr}$ have been gridded to produce the values shown in Figs. $4 \& 5$. The $t$-values used to determine statistical significance are the ratio of the gridded slopes divided by the gridded standard errors. Since each of these is derived from multiple stations, a relatively liberal level of type-I error ( $\alpha=0.10)$ was used. Using a variance response of $10 \%$ (i.e. regression slope of 0.1 ) as a threshold for what constitutes a scientifically meaningful relationship produces virtually no change in the maps.

\section{VARIANCE RESPONSE IN PROBABILITY DISTRIBUTIONS}

The sign and magnitude of the variance response have important implications for probability distributions of daily air temperature that can be expected under global warming conditions. With a change in variance, in addition to a change in mean, the shape and location of the probability distribution changes, producing nonlinear changes in event probabilities (Mearns et al. 1984). In addition, extreme events have been shown to be more sensitive to changes in variance than to changes in mean (Katz \& Brown 1992). Based on the analysis presented here, however, changes in standard deviation are only moderately sensitive to changes in mean temperature: for most 

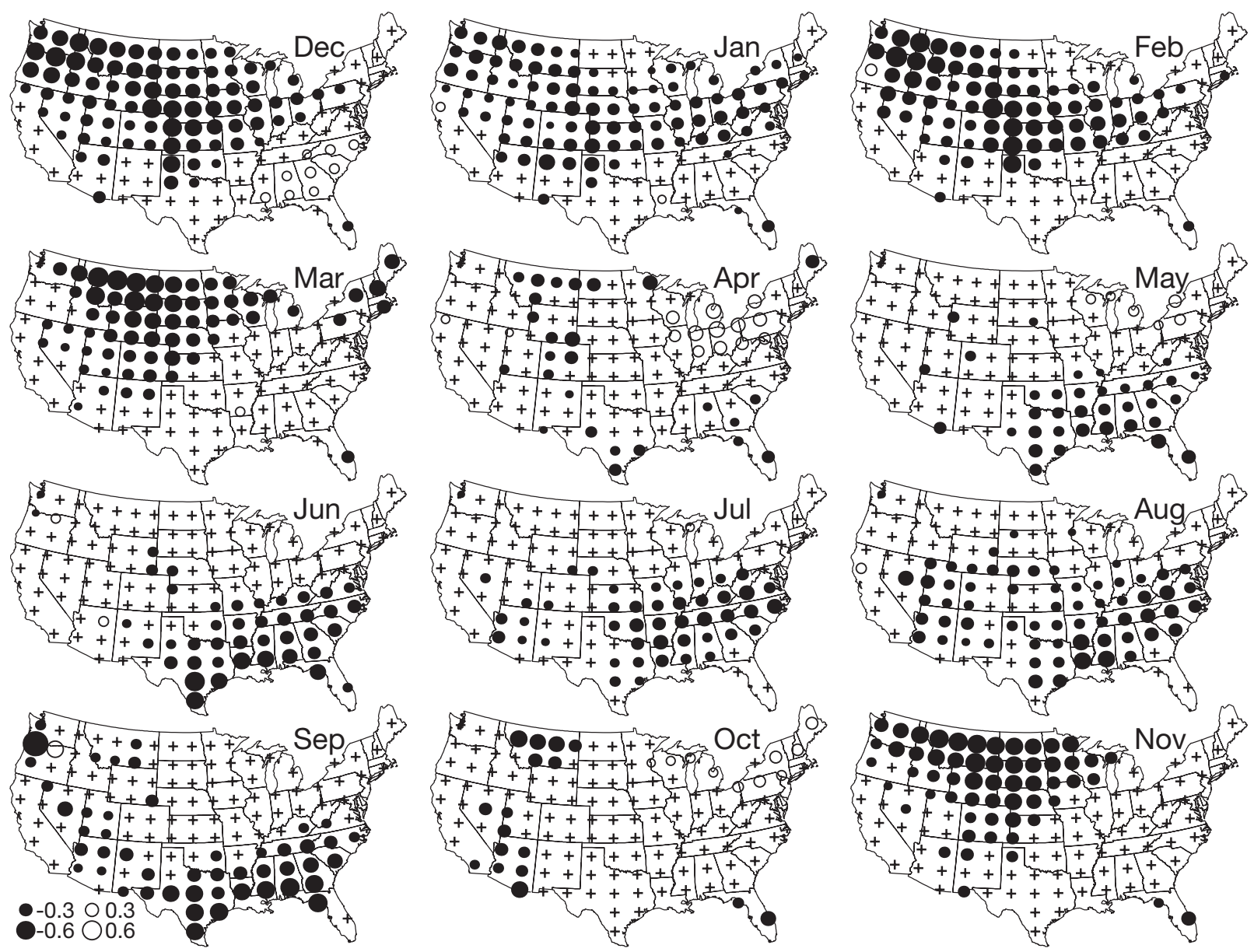

Fig. 5. As in Fig. 4, except data are daily minimum air temperature ( $\left.T_{\min }\right)$

locations in the contiguous USA, a $1^{\circ} \mathrm{C}$ change in mean temperature is associated with a 0.2 to $0.5^{\circ} \mathrm{C}$ change in standard deviation. The analog of urban warming, however, has demonstrated that simple shifts in the frequency distribution can overestimate the number of extreme high temperatures (Balling et al. 1990). In either case, simulations of changing probability distributions are needed to assess the specific impacts of changes in mean and variance.

As an example of a simulation that would be useful in a local or regional context, a scenario where the variance response is -0.4 and the mean air temperature increases by $3^{\circ} \mathrm{C}$ is used. This scenario, which results in a reduction of the standard deviation by $1.2^{\circ} \mathrm{C}$, produces no change-or even a small decrease - in the probability of high-temperature events (Fig. 7a). The negative variance response also produces a much lower probability of extreme cold events. The same mean temperature change of $3^{\circ} \mathrm{C}$, when combined with a positive variance response of 0.3 (thereby producing an increase in standard deviation of $0.9^{\circ} \mathrm{C}$ ), could vastly increase the probability of extremely high air temperatures, while producing little change in the probability of low air-temperature events (Fig. 7b). (Note that the negative variance response of -0.4 and positive variance response of 0.3 are used here because they are typical of the stronger variance responses seen in Figs. 4 \& 5.)

While the simulation of changes in probability distributions used here assumes a normal distribution, changes in the 2 tails may not be symmetrical. On a monthly timescale, daily air temperature is approximately normally distributed for most locations in the contiguous USA. If the extreme tails of the distribution are of interest, however, other probability distributions (Leadbetter et al. 1983) would be more appropriate. In addition, non-normal probability distributions (e.g. Barrow \& Hulme 1996, Horton et al. 2001), time-varying percentiles (Robeson 2002), or other parameters (such as skewness) are needed to evaluate the full range of shape changes in air-temperature probability distributions. Given an increasing mean and decreas- 

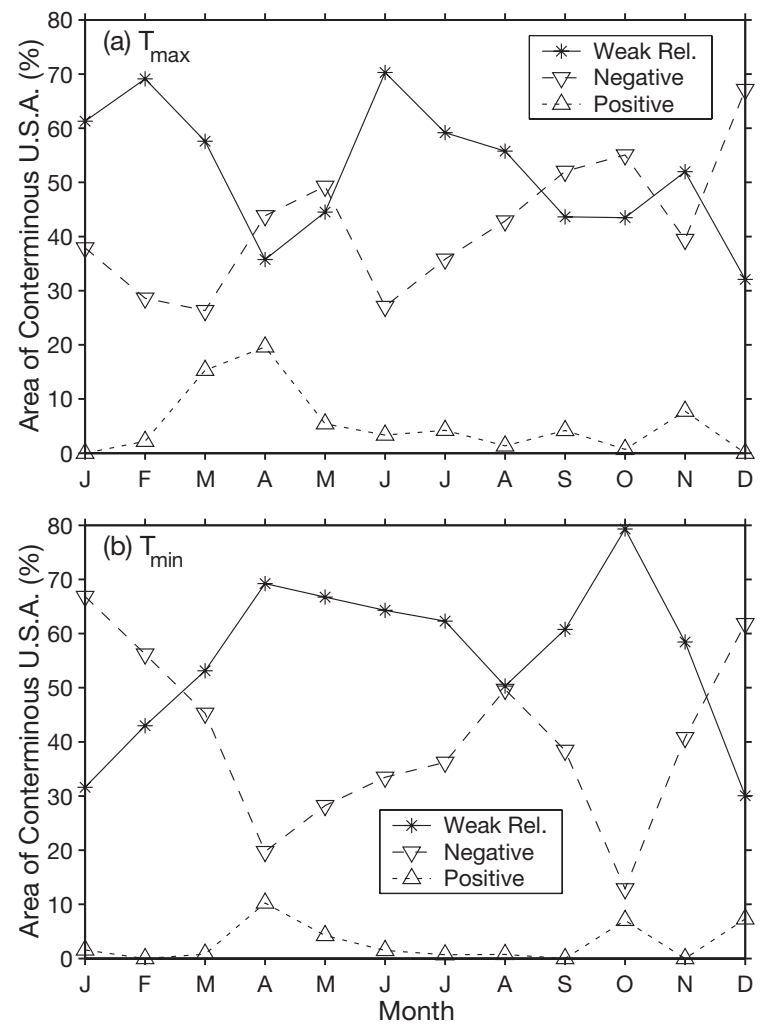

Fig. 6. Proportion of contiguous US that has a positive, negative, or weak (i.e. not statistically significant) variance response

ing variability, it is likely that the lower tail of probability distributions would be increasing faster than the upper tail. At the same time, it is important to distinguish between decreased air-temperature variability and changes in 'extremes' of air temperature (event probabilities). Depending on the magnitude of the warming and the variance response, upper-tail air temperatures that are considered to be extreme under current climatic conditions may still become more probable as air-temperature variability is reduced.

\section{FURTHER DISCUSSION}

Other studies have examined the relationship between mean and standard deviation of daily air temperature and standard deviation, albeit using lessextensive data sets and slightly different methods. Mearns et al. (1984) documented an inverse relationship between long-term mean maximum air temperature and its standard deviation for 4 stations in the north-central USA during summer months. The slope of their response was -0.305 , which was estimated from all 4 stations for all 3 summer months together (i.e. a single regression slope with $\mathrm{n}=12$ was used).
Considering that long-term statistics from multiple stations for multiple months were used to estimate the relationship, much of the response was attributed to variations caused by latitude and the annual cycle of air temperature variability (warmer months and southern locations have lower variance, colder months and northern locations have higher variance). The analysis presented here, in which individual months are used to estimate the variance response, produced little or no significant relationship between mean and standard deviation of air temperature at the locations studied by Mearns et al. (i.e. in the states of Indiana, Iowa, and North Dakota). Clearly, the type of historical analog used-multiple years at 1 location or latitudinal/seasonal variations at multiple locations - has a profound impact on the expected response of the climate system to changes in mean conditions.

Brinkmann (1983) estimated the correlation between mean and standard deviation of air temperature at 3 locations in Wisconsin. The overall pattern of variance response was similar to the one found here for the Wisconsin region: strong inverse relationship during winter and either no relationship or a weak positive relationship at other times of year. Brinkmann also demonstrated that the inverse relationship during winter was caused by the occurrence of a number of very cold
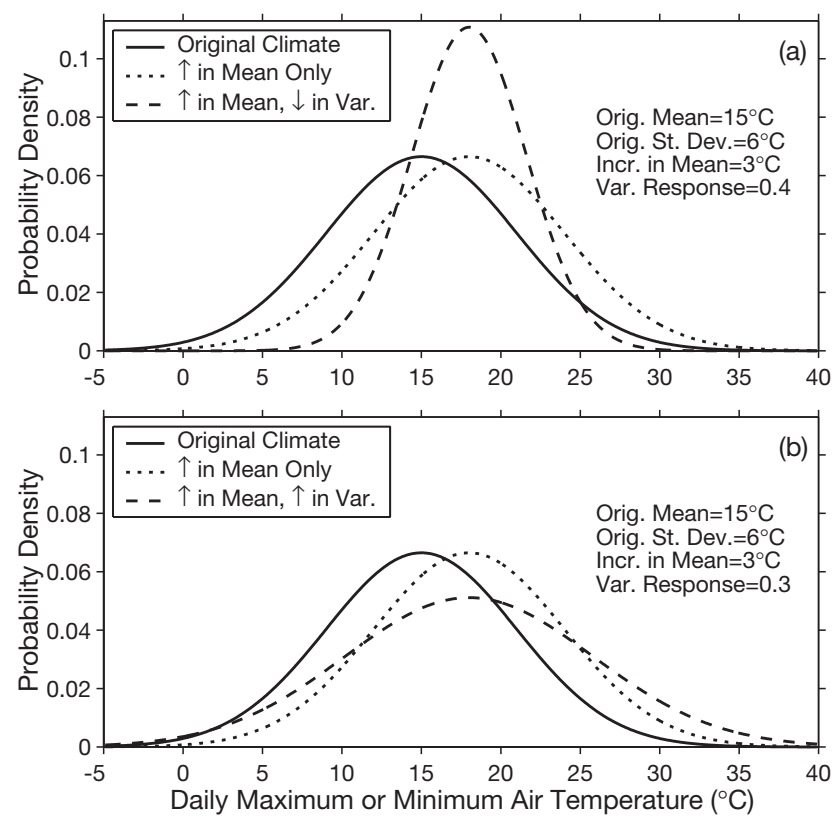

Fig. 7. Response of probability distributions to changes in mean and variance of daily air temperature (graphs can refer to either $T_{\max }$ or $T_{\min }$ depending on month and location). The original climate is perturbed by an increase in mean of $3^{\circ} \mathrm{C}$. Using (a) a negative variance response of -0.4 and (b) a positive variance response of 0.3 produces probability distributions that are substantially different from those that include changes in mean temperature only 
days during cold months and the lack of such cold days during warm months. The negative variance response that occurs over much of the USA likely has a similar interpretation: cold months do not simply have shifts of the probability distribution to a lower mean, they have an elongation of the lower tail that causes the increase in variability. The positive variance response that occurs in the Pacific Northwest and Great Lakes states (primarily during spring months) is likely caused by a related mechanism, except that warm events are the perturbation in the probability distribution. When these regions experience a series of unusually warm days in spring or fall, both mean and standard deviation increase through an elongation of the upper tail of the probability distribution while the lower tail remains approximately unchanged.

On a monthly timescale, variability in air temperature across most of the USA certainly is driven by the frequency, persistence, and strength of synoptic-scale circulations and associated advection processes. Synoptic-scale variations, in turn, cause variations in cloud cover, cloud type, humidity, and wind speed, which are key controlling mechanisms in the relationship between mean and standard deviation of air temperature. The fact that much recent research has shown positive trends in cloud cover (Henderson-Sellers 1986, 1992, Plantico et al. 1990, Karl et al. 1993) and humidity (Gaffen \& Ross 1999) lends further evidence for the expectation of reduced air-temperature variability under warming conditions. Drawing further on the negative variance response analogy, warmer months would be expected have (1) less-frequent coldfront passages or (2) cold fronts (or cold air masses) that are not as intense. While both of these conditions may be likely under global warming, differential warming in the coldest air masses and at the coldest times of year has been established (Kalkstein et al. 1990, Jones \& Briffa 1995, Knappenberger et al. 2001). Both situations (fewer cold-front passages, less-intense polar air masses) are consistent with scenarios of global warming that show warming in higher-latitude areas (especially during winter) and weaker equator-to-pole temperature gradients.

Certainly, using historical analogs is not without limitations. Historical analogs, nonetheless, can help us to evaluate a number of hypotheses and intuitions. For instance, one might initially think of the historical temperature/precipitation relationship as having an inverse relationship (droughts produce high temperatures and low precipitation; rainy days tend to be cooler, etc.), which is inconsistent with global warming scenarios that show enhanced precipitation (IPCC 2001). As with the mean/variance relationship, however, the temperature/precipitation relationship varies by month and location. Drawing on the work of Mad- den \& Williams (1978), Isaac \& Stuart (1992), and Zhao \& Khalil (1993), the historical temperature/precipitation relationship shows that summer months tend to have an inverse correlation. In winter, however, the correlation is, in general, positive. As a historical analog for global warming conditions, therefore, these results may be both useful and consistent with climatemodel simulations: much of the warming may occur in winter and therefore produce higher amounts of winter precipitation. What will happen in the summer months is less clear (e.g. see Fig. 10.6 in IPCC 2001). One limitation of a correlation-based historical ana$\log$-as was used in the 3 temperature/precipitation studies referenced above-is that one cannot say how sensitive precipitation is to variations in temperature, only that the 2 variables are inversely or directly related to one another (or unrelated to one another). Regression-based historical analogs should be used wherever possible.

\section{SUMMARY AND CONCLUSIONS}

For most of the contiguous USA, the slope of the relationship between the monthly mean and monthly standard deviation of daily $T_{\max }$ and $T_{\min }$ - the variance response-is either negative or near-zero. This suggests that, for most of the contiguous USA, a warming climate should produce either reduced air-temperature variability or no change in air-temperature variability. A portion of the northern tier of states has a positive variance response during some spring and fall months, indicating an increase in air-temperature variability under a warming climate. While limited in spatial extent, the positive variance response could produce a higher probability of low temperatures during late spring and early fall and, therefore, be particularly harmful to agriculture and native vegetation in northern states.

A negative variance response has the potential to mitigate some of the potential impacts of increasing mean air temperature, but only if these impacts are driven by upper-tail temperatures (high values of daily $T_{\max }$ or $T_{\min }$ ). Examples of impacts that would be mitigated by a less-severe increase in upper-tail temperatures include human and crop heat stress, as well as demand for electricity. Given a negative variance response and a warming (mean) climate, however, lower-tail temperatures would rise even more than they would be expected to under no change in variance. While in some cases this could be considered beneficial (e.g. fewer severely cold nights during winter), the potential for agricultural, environmental, and human impacts remains. Insect pests, for instance, would be less likely to be killed during winter. Lakes 
that previously froze during winter may no longer freeze, resulting in increased evaporation and lower lake levels. Some areas of the contiguous USA also could experience greater reductions in seasonal snow cover than would be anticipated based on mean airtemperature changes alone.

This research has focused on the nature of the relationship between mean and standard deviation of air temperature in the contiguous USA. Clearly, when compared to the assumption of no change in air-temperature variance under a warming climate, there can be very different impacts, depending on the sign and magnitude of the response. In addition to modeling studies and theoretical analyses of the variance response, further empirical research should examine the variance response over longer timescales and in other locations. A better understanding of historical air-temperature variability certainly will require more-complete daily air temperature data sets than currently are available.

Acknowledgements. Portions of this research were supported by the National Science Foundation under Grant No. BCS0136161.

\section{LITERATURE CITED}

Balling RC Jr, Skindlov JA, Phillips DH (1990) The impact of increasing summer mean temperatures on extreme maximum and minimum temperatures in Phoenix, Arizona. J Clim 3:1491-1494

Barrow EM, Hulme M (1996) Changing probabilities of daily air temperature extremes in the UK related to future global warming and changes in climate variability. Clim Res 6:21-31

Brinkmann WAR (1983) Variability of temperature in Wisconsin. Mon Weather Rev 111:172-179

Cooter EJ, LeDuc SK (1995) Recent frost date trends in the north-eastern USA. Int J Climatol 15:65-75

Davis JC (1986) Statistics and data analysis in geology, 2nd edn. John Wiley \& Sons, NY

Easterling DR, Karl TR, Lawrimore JH, Del Greco SA (1999) United States historical climatology network daily temperature, precipitation, and snow data for 1871-1997. ORNL/CDIAC-118, NDP-070. Carbon Dioxide Information Analysis Center, Oak Ridge National Laboratory, US Department of Energy, Oak Ridge, TN

Easterling DR, Evans JL, Groisman PYa, Karl TR, Kunkel KE, Ambenje P (2000) Observed variability and trends in extreme climate events: a brief review. Bull Am Meteorol Soc 81:417-425

Gaffen DJ, Ross RJ (1999) Climatology and trends in U.S. surface humidity and temperature J Clim 12:811-828

Glantz MH (ed) (1988) Societal responses to regional climatic change: forecasting by analogy. Westview Press, Boulder, $\mathrm{CO}$

Henderson-Sellers A (1986) Increasing clouds in a warming world. Clim Change 9:267-309

Editorial responsibility: Hans von Storch, Geesthacht, Germany
Henderson-Sellers A (1992) Continental cloudiness changes this century. GeoJournal 27:255-262

Horton EB, Folland CK, Parker DE (2001) The changing incidence of extremes in worldwide and central England temperatures to the end of the twentieth century. Clim Change 50:267-295

Intergovernmental Panel on Climate Change (IPCC) (2001) Climate change 2001: the scientific basis, 2001. Cambridge University Press, Cambridge

Isaac GA, Stuart RA (1992) Temperature-precipitation relationships for Canadian stations. J Clim 5:822-830

Jones PD, Briffa KR (1995) Growing season temperatures over the former Soviet Union. Int J Climatol 15:943-959

Jones PD, Horton EB, Folland CK, Hulme M, Parker DE, Basnett TA (1999) The use of indices to identify changes in climatic extremes. Clim Change 42:31-149

Kalkstein LS, Dunne PC, Vose RS (1990) Detection of climatic change in the western North American Arctic using a synoptic climatological approach. J Clim 3:1153-1167

Karl TR, Easterling DR (1999) Climate extremes: selected review and future research directions. Clim Change 42: 309-325

Karl TR, Williams CN Jr, Quinlan FT, Boden TA (1990) United States Historical Climatology Network (HCN) serial temperature and precipitation data. Carbon Dioxide Information and Analysis Center, Oak Ridge National Laboratory, US Department of Energy, Oak Ridge, TN

Karl TR, Jones PD, Knight RW, Kukla G and 6 others (1993) A new perspective on recent global warming: asymmetric trends of daily maximum and minimum temperature. Bull Am Meteorol Soc 74:1007-1023

Karl TR, Nicholls N, Gregory J (1997) The coming climate. Sci Am 276:78-83

Katz RW, Brown BG (1992) Extreme events in a changing climate: variability is more important than averages. Clim Change 21:289-302

Knappenberger PC, Michaels PJ, Davis RE (2001) Nature of observed temperature changes across the United States during the 20th century. Clim Res 17:45-53

Leadbetter MR, Lindgren G, Rootzen H (1983) Extremes and related properties of random sequences and processes. Springer-Verlag, New York

Madden RA, Williams J (1978) The correlation between temperature and precipitation in the United States and Europe. Mon Weather Rev 106:142-147

Mark DM, Church M (1977) On the misuse of regression in earth science. Math Geol 9:63-75

Mearns L, Katz R, Schneider S (1984) Extreme high-temperature events: changes in their probabilities with changes in mean temperature. J Clim Appl Meteorol 23: $1601-1613$

Peterson TC, Easterling DR, Karl TR, Groisman P and 17 others (1998) Homogeneity adjustments of in situ atmospheric climate data: a review. Int J Climatol 18:1493-1517

Plantico MS, Karl TR, Kukla G, Gavin J (1990) Is recent climate change across the United States related to rising levels of anthropogenic greenhouse gases? J Geophys Res 95: $16617-16637$

Robeson SM (2002) Increasing growing-season length in Illinois during the 20th century. Clim Change 52:219-238

Zhao W, Khalil MAK (1993) The relationship between precipitation and temperature over the contiguous United States. J Clim 6:1232-1236

Submitted: Decenber 19, 2001; Accepted: July 9, 2002 Proofs received from author(s): September 27, 2002 